\title{
Diferenciais de gênero no impacto do arranjo familiar no status de saúde dos idosos brasileiros*
}

\author{
Gender differences in the impact of family \\ arrangements on health status of Brazilian elderly
}

Dalia E. Romero 1

\footnotetext{
* Este trabalho teve apoio do convênio Fiocruz-Faperj. 1 Departamento de Informações em Saúde, Fundação Oswaldo Cruz. CICT/Fiocruz. Av. Brasil 4365, 21045-900 Rio de Janeiro RJ. dalia@cict.fiocruz.br
}

Abstract In this work one explores gender differences in family arrangement and its relation to the health status of men and women over 65, taking into account socio-demographic and socioeconomic variables. Data were collected through a National Household Survey in 1998 that included a special supplement on health. Several logistic regression models were run for two dependent variables: health self assessment and report of chronic conditions. The explanatory variables (urban/rural area, age, per capita income, illiteracy, family arrangement, and household condition) were incorporated in a sequential way to assess changes in the relationship. It was found that, although women report more chronic conditions, there is a relative similarity in health self-assessment for both women and men. Gender differences in family arrangements patterns are partially responsible for the poorer health status of women. Health policies oriented to the older people must take into consideration the existent of important gender differences in family structure and family arrangements. There is a need of more detailed information on Brazilian household surveys as to disentangle the relationships between the older people's health, gender and family.

Key words Gender, Elderly, Health status, Family arrangements, Socioeconomic conditions
Resumo Analisam-se os diferenciais por gênero na relação do arranjo familiar com o status de saúde de pessoas com 65 anos ou mais, incorporando também fatores socioeconômicos e sociodemográficos. Utilizam-se dados da PNAD de 1998. Foram desenvolvidos diversos modelos de regressão logística para duas variáveis dependentes: auto-avaliação da saúde e declaração de doenças. Os fatores explicativos (área rural/urbana, idade, renda per capita, analfabetismo, arranjo familiar e condição no domicílio) foram incorporados seqüencialmente para avaliar as mudanças da inter-relação. Encontrou-se que, embora as mulheres tenham mais desvantagem quanto à declaração de doenças, a auto-avaliação da condição de sua saúde é relativamente similar à dos homens. Os diferenciais de gênero no padrão de arranjo familiar dos idosos são em parte responsáveis pela desvantagem no status de saúde das mulheres. Conclui-se que a formulação de politicas para o melhoramento do status de saúde do idoso deve considerar a existência de importantes diferenças de gênero no padrão da estrutura e arranjo de suas famílias. Existe necessidade de maior disponibilidade de inquéritos para idosos, que permitam aprofundamento na relação entre saúde do idoso, gênero e família.

Palavras-chave Gênero, Idoso, Status de saúde, Arranjo familiar, Fatores socioeconômicos 


\section{Introdução}

Nos países "desenvolvidos" existe uma diversidade de pesquisas que tem explorado o impacto da família, o suporte social e as redes de relações sociais na saúde e mortalidade dos idosos (Berkman \& Syme, 1979; Blazer, 1982; Grundy et al., 1996; Shye et al., 1995). Embora quando comparados esses trabalhos não apresentem conclusões definitivas quanto à direção, temporalidade e intensidade da relação desses eventos, devido às diferentes definições e opções metodológicas e diversidade nos instrumentos utilizados (Bowling, 1991; Litwin, 1998), seus resultados sugerem que o contexto social formado pela unidade doméstica pode ser sumamente importante na etiologia social da saúde (Hughes \& Waite, 2002).

Alguns têm apontado a existência da reciprocidade entre a saúde das pessoas idosas e a estrutura e conformação das relações sociais e familiares, já que, por um lado, a deterioração da saúde pode levar a redefinir os arranjos familiares, assim como certas estruturas familiares; e pelo outro, o tipo e características da rede social e familiar pode levar a diferentes riscos de doenças e morte (Auslander \& Litwin, 1990; Mor-Barak \& Miller, 1991).

Entretanto, não existe certeza de que uma determinada combinação de suporte e estrutura familiar favoreça mais a saúde dos idosos. Rahman (1999), num estudo com dados prospectivos da população rural de Bangladesh, demonstrou que, depois de controlar por idade e incapacidades, é determinante para a mortalidade a presença do cônjuge e/ou de filhos no domicílio, assim como também o tipo de relação com o chefe da família. Litwin (1998), com uma amostra de um inquérito nacional de pessoas de 60 anos e mais em Israel, observou que a maior diversidade das redes sociais (amigos, vizinhos, comunidade religiosa e família) melhora a qualidade da saúde dos idosos. Uma constante participação em serviços religiosos foi apontado como fator com maior efeito protetor da mortalidade dos idosos do que um alto suporte social (Omam \& Reed, 1998). De Vos \& Holden (1988) afirmam que a composição da unidade doméstica do idoso define em grande parte sua capacidade e disposição física, o grau de dependência e a assistência cotidiana: transporte, cuidados médicos, serviços e manutenção da casa. Por outra parte, tem se mostrado que os idosos que vivem com familiares (incluindo o esposo) estão melhor, não só quanto à renda familiar, como também quanto ao acesso à assistência da vida cotidiana (Holden, 1988). Nos países menos desenvolvidos, como os países latino-americanos, escasseiam estudos sobre o impacto na mortalidade e na saúde do idoso, na estrutura familiar e nas redes sociais de apoio. No Brasil são recentes os estudos sobre relações intergeneracionais, especialmente o que se refere ao suporte dos idosos para as gerações mais novas (Camarano \& Ghaouri, 1999).

Embora se aceite o slogan "mulher adoece mais, porém homem morre mais rápido" (Lahelma et al., 1999) e se creia que a velhice é uma experiência diferente para homens e para mulheres, tanto na sua subjetividade como nas condições de vida, doença e morte, a literatura sobre diferenciais de saúde dos idosos que incorporam enfoque de gênero não é suficiente (Shye et al., 1995; Rahman, 1999). Nesse sentido, Arber \& Cooper (1999) comentam que essa omissão é irônica, não só porque é bem maior o número de mulheres, cujo peso populacional vai aumentando nas últimas faixas etárias da vida, mas também porque as mulheres idosas, comparadas com os homens, têm grandes desvantagens na severidade das incapacidades e nos seus arranjos familiares.

O estudo do determinante potencial do gênero na relação entre status de saúde e arranjo familiar não deve deixar de incorporar (Lahelma et al., 1999) fatores que caracterizem as desigualdades por sexo ante as condições socioeconômicas e estruturais, como, por exemplo, às condições domésticas e a renda familiar (Rahman, 1999; Bartley et al., 1992). Assim, neste trabalho de análise multivariada, incorporam-se progressiva e simultaneamente variáveis contextuais para avaliação de seu efeito na relação entre status de saúde e gênero dos idosos no Brasil.

Por outra parte, sendo de fácil e simples captação em inquéritos de saúde, a autopercepção da saúde é um indicador da qualidade de vida e da morbidade e um importante preditor da subseqüente mortalidade, pelo qual tem merecido considerável interesse em pesquisas durante as últimas três décadas (Manderbacka et al., 2002). Essa associação foi demonstrada para a população em geral (Kaplan \& Camacho, 1983; Idler \& Benyamini, 1997) e especialmente para a população idosa (Mossey \& Shapiro, 1982; Bryant et al., 2000). A interpretação da auto-avaliação da saúde varia por idade e gênero (Idler, 1993; Jylhä et al., 1998; Westerhof et al., 2001; Molarius \& Janson, 2002) e incorpora uma variedade de componentes físicos, cultu- 
rais e emocionais (Idler \& Benyamini, 1997; Westerhof et al., 2001). Segundo sugestões de diversos autores (Lahelma et al., 1999; Arber \& Cooper, 1999), no presente estudo usam-se diferentes medidas de autopercepção do estado de saúde com a finalidade de avaliar se há modificação quanto à relação por gênero em função da medida utilizada.

Os objetivos principais deste trabalho são, primeiramente, examinar a intensidade e natureza da desigualdade por gênero no status de saúde percebido pelo idoso, focalizando como as diferenças por gênero variam de acordo com a medida de status de saúde usada (morbidade auto-referida e auto-avaliação da condição da saúde). Em segundo lugar, e não menos importante, estudam-se as diferenças por gênero na relação entre status de saúde e arranjo familiar na presença de fatores econômicos, sociais e demográficos e observam-se modificações no peso desses fatores quando introduzidas características da família do idoso.

\section{Métodos}

Este trabalho baseia-se nos microdados da Pesquisa Nacional por Amostra de Domicílios (PNAD) de 1998, conduzida pelo Instituto Brasileiro de Geografia e Estatística (IBGE). A PNAD/98 é um inquérito representativo em nível nacional aplicado a 344.975 pessoas moradoras de 112.434 domicílios (IBGE, 2000). Contém um módulo especial sobre saúde, além dos módulos sobre características do domicílio, dos indivíduos, da migração, da educação, do trabalho e da fecundidade. Para garantir a representatividade da população total, utilizaram-se os pesos relativos da amostra obtidos da divisão dos pesos de expansão pela média dos pesos (Lee et al., 1989). Selecionaram-se pessoas de 65 anos e mais $(n=19727)$, o correspondente a $5,7 \%$ da amostra.

O status de saúde do idoso foi analisado por meio de duas variáveis respostas dicotômicas. A primeira delas, “declarar-se doente”, é uma aproximação do estado mórbido do idoso. Esta variável foi mensurada a partir da resposta afirmativa a alguma das doze enfermidades crônicas perguntadas na PNAD/98: doença de coluna ou costas, artrite ou reumatismo, câncer, diabetes, bronquites ou asma, hipertensão (pressão alta), doença do coração, doença renal crônica, depressão, tuberculose, tendinite, tenossinovite ou cirrose. A segunda variável, auto-avaliação da saúde, foi obtida a partir da resposta à pergunta que pedia para descrever seu próprio estado de saúde como "muito bom", "bom", "regular", "ruim" ou "muito ruim". A medida selecionada foi à auto-avaliação deficiente no caso de respostas com alguma das três últimas opções.

$\mathrm{Na}$ PNAD/98 identificam-se as relações das pessoas na unidade doméstica segundo dois agrupamentos: em relação ao domicílio e em relação à família, sendo que este último conceito aproxima-se muito da idéia de família nuclear ou de família conjugal. Por exemplo, o fato de um casal de idosos morar junto com sua filha, genro e netos determinaria a existência de duas famílias. Como neste trabalho pretende-se captar o arranjo familiar do idoso na unidade doméstica, decidiu-se trabalhar com o domicilio como unidade de referência da conformação da unidade familiar intradomiciliar. Para uma discussão mais detalhada sobre o conceito de família, domicílio e arranjos familiares nas PNADs, recomenda-se consultar o trabalho de Medeiros et al. (2002).

Consideram-se diferentes variáveis dicotômicas que dão conta dos arranjos domiciliares: a) mora com alguém ou mora sozinho; b) mora só com cônjuge ou não mora só com cônjuge; c) mora com cônjuge ou cônjuge ausente; d) mora sem filho de 18 anos e mais ou mora com algum filho de 18 anos e mais; e) mora com algum menor de 18 anos ou não mora com menor de 18 anos. A condição de parentesco no domicílio é trabalhada com duas variáveis dicotômicas: a) chefe no domicílio ou não é chefe do domicílio (sendo que a categoria chefe é nomeada na PNAD/98 como pessoa de referencia); b) agregado/outro parente da pessoa de referência no domicílio ou não é agregado ou outro parente. A boa qualidade e consistência dos dados sobre família e composição do domicilio das PNADs foram testadas por Medeiros et al. (2002).

O status socioeconômico foi mensurado através da renda per capita (RPC) no domicílio do idoso. Definiram-se três categorias: com mais de cinco salários-mínimos (SM), de dois a cinco SM e menos de dois SM. Outro indicador que dá conta não só da situação socioeconômica, mas também das oportunidades e experiências no ciclo vital do idoso é a escolaridade obtida, a qual é mensurada neste trabalho pela condição de analfabetismo ou alfabetismo. A raça (definida na PNAD pelo entrevistado) se incorporou como variável com duas categorias: de raça branca ou de outra raça não branca. 
Algumas variáveis sociodemográficas são consideradas. A urbanização se identificou com duas categorias: urbano e rural. Como o segmento idoso compreende um intervalo etário amplo, aproximadamente 30 anos, distinguemse dois grupos (idosos/jovens, de 65 a 75 anos, e os mais idosos, maiores de 75 anos), para se verificar se um ou outro grupo tem efeito nos modelos testados.

Para estudar os diferenciais por gênero da influência simultânea no status da saúde dos idosos, dos arranjos domiciliares e das condições socioeconômicas e demográficas, foi usada a regressão logística, uma vez que as duas variáveis respostas definiram-se de forma dicotômica. Incorporou-se o sexo como co-variável no primeiro set de modelos e replicaram-se todos os modelos para cada sexo em separado. Adotou-se um processo de seleção de inclusão seqüencial das variáveis (stepwise forward) estimado pela razão de verossimilhança no software SPSS 10.0. Tal critério considera a estatística $\mathrm{D}$ (deviância) para escolher as variáveis que entram no modelo. Tendo inicialmente o modelo sem restrições (só com a constante $\beta_{0}$ ), incorporam-se seqüencialmente no modelo, uma a uma, as variáveis que passam a caracterizar, naquele contexto, o status de saúde do idoso, com um nível de significância menor que 0,05 . Os resultados são avaliados a partir da Razão de Chance ou odds ratio (OR) com intervalos de confiança de $95 \%$. A razão de chance menor que 1 significa que a variável está funcionando como "protetor" daquele risco; quando, porém, a razão de chance é maior que 1, a variável está atuando como fator de risco.

Foram testados diversos modelos multivariados, que incluem de forma seqüencial os fatores socioeconômicos e sociodemográficos. A variável "informante das perguntas de saúde" da PNAD/98 permite controlar o efeito produzido pelas respostas dadas por outras pessoas na relação estudada. Apresentam-se tabelas separadas para o total, para homens e para mulheres quando a variável dependente é a morbidade. Quando a variável resposta é a auto-avaliação negativa da saúde, embora tenham sido também testados diferentes modelos para cada sexo, colocam-se só aqueles fatores que mostraram uma interação significativa.

\section{Resultados}

Na tabela 1, apresentam-se estatísticas descritivas segundo gênero, relativas a algumas variá- veis de condições socioeconômicas, de arranjo familiar e de indicadores do status de saúde consideradas neste estudo. A maioria dos idosos é menor de 75 anos (6 de cada 10), sendo que, em média, as mulheres são mais velhas do que os homens (32,8 e 36,2 maiores de 75 anos, respectivamente). A alta magnitude do analfabetismo, mais pronunciado nas mulheres (42\%), e a baixa renda per capita de suas famílias (cerca de $60 \%$ recebem menos de dois salários-mínimos ao mês) são expressões da pobreza de grande parte dos idosos brasileiros. Nota-se que a grande maioria mora em áreas urbanas e se declara de raça branca.

Destacam-se diferenças entre gênero em relação ao arranjo familiar dos idosos, assim como sobre a condição que ocupam no domicílio. Enquanto a grande maioria dos homens idosos mora com seu cônjuge $(80,9 \%)$ e são chefes ou pessoa de referência da família $(87,5 \%)$, as mulheres idosas distribuem-se em diversas opções de arranjo familiar: $46 \%$ moram com seu cônjuge; $23,5 \%$ moram com filhos e sem cônjuge; $13,7 \%$ moram apenas com um parente; e 16,7\% delas moram sozinhas. Morar só com o cônjuge é mais freqüente entre os homens do que entre as mulheres (32,6 e 17,6\% respectivamente), enquanto é similar entre gênero a proporção de idosos morando com um filho adulto e a presença no domicílio de um menor (cerca de 33\% para os dos indicadores assinalados). Das mulheres que não moram sozinhas, $37,6 \%$ são cônjuge do chefe e $33,8 \%$ são chefes no domicílio. É relevante que 27,3\% das mulheres idosas têm outro parentesco com o chefe do domicílio.

A apreciação das estatísticas relativas à saúde (Tabela 2) revela que, tanto para as mulheres como para os homens, as perguntas dessa seção foram respondidas na maioria dos casos pelo próprio idoso. E que as mulheres avaliam pior sua saúde e declaram mais doenças que os homens: $63 \%$ das mulheres e $48 \%$ dos homens declaram ter mais de uma das doenças incluídas entre as perguntas da $\mathrm{PNAD} / 98$. Quanto à morbidade auto-referida, notam-se certas semelhanças entre gênero na declaração de doenças como dores de coluna ou das costas, bronquite ou asma, doença renal crônica. A hipertensão, artrite, depressão e diabetes são mais referidas por mulheres. Dessas, a depressão é a mais acentuada entre o sexo feminino quando comparadas em termos proporcionais com a declaração de depressão entre os homens.

Nas tabelas de 3 a 6 encontram-se as razões de chance (odds ratio) obtidas dos procedimen- 
Tabela 1

Distribuição percentual dos idosos na amostra da PNAD/98 segundo as categorias das variáveis socioeconômicas e sociodemográficas. Brasil, 1998.

\begin{tabular}{|c|c|c|c|}
\hline & Total & Homens & Mulheres \\
\hline População idosa da PNAD/98* & 20.748 & 9.082 & 11.667 \\
\hline \multicolumn{4}{|l|}{ Grupo de idade idoso } \\
\hline $65-69$ & 37.8 & 39.8 & 36.2 \\
\hline $70-74$ & 27.5 & 27.4 & 27.6 \\
\hline $75-80$ & 17.1 & 17.3 & 17.0 \\
\hline $80+$ & 17.6 & 15.5 & 19.2 \\
\hline \multicolumn{4}{|l|}{ Sabe ler e escrever? } \\
\hline Não (analfabetas) & 39.2 & 35.6 & 42.0 \\
\hline Sim (alfabetas) & 60.8 & 64.4 & 58.0 \\
\hline \multicolumn{4}{|l|}{ Rendimento familiar per capita (RFPC) } \\
\hline Menor a 2 salários-mínimos & 61.9 & 63.0 & 61.1 \\
\hline de 2 a 5 salários-mínimos & 21.9 & 21.6 & 22.2 \\
\hline 5 e mais salários-mínimos & 16.2 & 15.4 & 16.7 \\
\hline \multicolumn{4}{|l|}{ Aporte do idoso na Renda Familiar (RF) } \\
\hline Não aportam & 10.4 & 3.2 & 16.0 \\
\hline Aportam de 1 a $50 \%$ da RF & 44.4 & 38.8 & 48.8 \\
\hline Aportam o $100 \%$ da RF & 28.2 & 32.0 & 25.3 \\
\hline \multicolumn{4}{|l|}{ Região } \\
\hline Urbana & 79.0 & 75.7 & 81.5 \\
\hline Rural & 21.0 & 24.3 & 18.5 \\
\hline \multicolumn{4}{|l|}{ Raça } \\
\hline Branca & 61.6 & 60.2 & 62.7 \\
\hline Não Branca & 38.4 & 39.8 & 37.3 \\
\hline \multicolumn{4}{|l|}{ Arranjo familiar } \\
\hline Mora casal s/filhos & 31.2 & 40.6 & 23.8 \\
\hline Mora casal c/filhos & 30.1 & 40.3 & 22.2 \\
\hline Sem cônjuge c/filhos & 16.4 & 7.1 & 23.5 \\
\hline Sem cônjuge s/ filho c/parente & 9.2 & 3.3 & 13.7 \\
\hline Mora sozinho & 13.2 & 8.7 & 16.7 \\
\hline mora só com cônjuge (a) & 24.2 & 32.6 & 17.6 \\
\hline mora com pelo menos um filho de 18 anos ou mais & 33.3 & 33.0 & 33.6 \\
\hline mora com menores de 18 anos & 32.7 & 33.3 & 32.1 \\
\hline \multicolumn{4}{|l|}{ Número de famílias no domicílio } \\
\hline Uma & 98.22 & 98.34 & 98.12 \\
\hline Mais de uma & 1.78 & 1.66 & 1.88 \\
\hline \multicolumn{4}{|l|}{ Condição no domicílio ${ }^{* *}$} \\
\hline chefe & 58.4 & 87.5 & 33.8 \\
\hline cônjuge & 21.5 & 2.5 & 37.6 \\
\hline outro parente & 19.0 & 9.2 & 27.3 \\
\hline agregado & 1.0 & 0.9 & 1.2 \\
\hline
\end{tabular}

* Amostra ponderada com os pesos proporcionais.

** Excluem-se pessoas que moram sozinhas as quais foram classificadas nessa variável como chefe. 
Tabela 2

Distribuição percentual dos idosos na amostra da PNAD/98 segundo as categorias das variáveis de arranjo familiar e condição no domicílio. Brasil, 1998.

\begin{tabular}{|c|c|c|c|}
\hline & Total & Homens & Mulheres \\
\hline População idosa da PNAD/98* & 20.748 .4 & 9.081 .7 & 11.666 .7 \\
\hline \multicolumn{4}{|l|}{ Informante das perguntas de saúde } \\
\hline Própria pessoa & 64.0 & 60.4 & 66.9 \\
\hline Outra pessoa & 36.0 & 39.6 & 33.1 \\
\hline \multicolumn{4}{|l|}{ Considera seu estado de saúde } \\
\hline Muito bom & 5.8 & 6.4 & 5.3 \\
\hline Bom & 30.7 & 33.1 & 28.9 \\
\hline Regular & 45.2 & 43.1 & 46.8 \\
\hline Ruim ou Muito ruim & 18.3 & 17.5 & 19.0 \\
\hline \multicolumn{4}{|c|}{ Número de doenças crônicas reportadas } \\
\hline Nenhuma & 19.5 & 24.1 & 16.0 \\
\hline 1 doença & 24.1 & 27.9 & 21.2 \\
\hline 2 doenças & 23.4 & 21.9 & 24.5 \\
\hline 3 doenças & 16.7 & 13.9 & 18.8 \\
\hline 4 e mais doenças & 16.3 & 12.2 & 19.6 \\
\hline \multicolumn{4}{|l|}{ Morbidade auto-referida } \\
\hline dores de coluna ou das costas & 45.7 & 42.5 & 48.2 \\
\hline hipertensão & 45.4 & 37.9 & 51.3 \\
\hline artrite ou reumatismo & 40.0 & 32.7 & 45.7 \\
\hline doença do coração & 20.8 & 18.3 & 22.8 \\
\hline depressão & 11.9 & 8.1 & 14.9 \\
\hline diabetes & 10.8 & 8.3 & 12.8 \\
\hline bronquite ou asma & 8.6 & 8.9 & 8.3 \\
\hline doença renal crônica & 6.9 & 7.0 & 6.8 \\
\hline tendinite ou tenossinovite & 4.5 & 3.4 & 5.4 \\
\hline câncer & 1.2 & 1.5 & 1.0 \\
\hline cirrose & 0.3 & 0.4 & 0.2 \\
\hline tuberculose & 0.2 & 0.3 & 0.1 \\
\hline
\end{tabular}

* Amostra ponderada com os pesos proporcionais.

tos de regressão logística, com as categorias referenciais iguais a 1 . Os resultados apontam uma série de observações. Entre as principais, estão as que se seguem.

O gênero tem grande força explicativa do status de saúde declarado pelos idosos, especialmente da morbidade percebida. O risco de "declarar-se doente" e o risco de auto-avaliar sua saúde de forma deficiente é menor entre os homens do que entre as mulheres (em 39\% e 20\% respectivamente, Tabela 3 e Tabela 6). Essa diferença por gênero é estatisticamente significativa $(p<0,01)$. Os homens declaram-se menos doentes que as mulheres, independentemente da pessoa que responde às perguntas sobre as doenças e mesmo controlando por idade, status socioeconômico e arranjos familiares. Esse efeito protetor do sexo masculino é sempre signifi- cativo e varia entre os modelos, sendo quase $50 \%$ menor a chance de os homens declararem doença quando se incorpora a presença de filhos maiores de 18 anos e de menores de 18 anos (Tabela 3, modelo 7, odds=0,54). Outra forma de avaliar a importância do gênero, no status de saúde, é observando que os modelos testados para a variável que dá conta da morbidade auto-referida "declarar-se doente" são diferentes quando estimados para cada sexo ( Tabela 4 e Tabela 5), assim como não muda o efeito da variável sexo com a entrada no modelo da idade (modelo 2, Tabela 3). O último também sugere que o fato de a mulher ser mais idosa (mais idade em média) não explicaria diferenças por gênero do status de saúde.

A condição socioeconômica do idoso está altamente associada com o status de saúde re- 
Tabela 3

Razão de chance (odds) dos modelos logísticos para pessoas idosas que se declaram doente. ${ }^{1}$

\begin{tabular}{|c|c|c|c|c|c|c|c|c|}
\hline & Modelo 1 & IC 95\% & Modelo 2 & IC $95 \%$ & Modelo 3 & IC $95 \%$ & Modelo 4 & IC $95 \%$ \\
\hline \multicolumn{9}{|l|}{ Informante da seção de saúde } \\
\hline Própria pessoa & 1,00 & & 1,00 & & 1,00 & & 1,00 & \\
\hline Outra pessoa & $1,27^{\star}$ & $(1,18-1,36)$ & $1,29^{*}$ & $(1,20-1,39)$ & $1,25^{\star}$ & $(1,16-1,34)$ & $1,25^{\star}$ & $(1,16-1,34)$ \\
\hline \multicolumn{9}{|l|}{ Sexo } \\
\hline Mulheres & 1,00 & & 1,00 & & 1,00 & & 1,00 & \\
\hline Homens & $0,61^{\star}$ & $(0,57-0,65)$ & $0,61^{\star}$ & $(0,57-0,65)$ & $0,61^{\star}$ & $(0,57-0,65)$ & $0,61^{\star}$ & $(0,57-0,65)$ \\
\hline \multicolumn{9}{|l|}{ Idade } \\
\hline Menos 75 anos & - & & 1 & & 1 & & 1 & \\
\hline De 75 anos e mais & & & $1,16^{\star}$ & $(1,08-1,25)$ & $1,12^{\star}$ & $(1,04-1,21)$ & $1,12^{\star}$ & $(1,04-1,21)$ \\
\hline Status socioeconômico & & & & & & & & \\
\hline $\mathrm{RPC}$ mais de $5 \mathrm{SM}$ & - & & - & & 1 & & 1 & \\
\hline RPC menor $2 \mathrm{SM}$ & & & & & $1,51^{\star}$ & $(1,37-1,66)$ & $1,51^{\star}$ & $(1,37-1,66)$ \\
\hline $\mathrm{RPC}$ de 2 a $5 \mathrm{SM}$ & & & & & $1,26^{*}$ & $(1,13-1,40)$ & $1,26^{*}$ & $(1,13-1,40)$ \\
\hline Alfabetas & - & & - & & 1 & & 1 & \\
\hline Analfabetas & & & & & $1,21^{\star}$ & $(1,12-1,31)$ & $1,22^{*}$ & $(1,12-1,32)$ \\
\hline \multicolumn{9}{|l|}{ Arranjo familiar } \\
\hline $\begin{array}{l}\text { Mora com alguém } \\
\text { Mora sozinho }\end{array}$ & - & & - & & - & & NS & \\
\hline $\begin{array}{l}\text { Não mora só com cônjuge } \\
\text { Mora só com cônjuge }\end{array}$ & - & & - & & - & & - & \\
\hline $\begin{array}{l}\text { Mora sem cônjuge } \\
\text { Mora com cônjuge }\end{array}$ & - & & - & & - & & - & \\
\hline $\begin{array}{l}\text { Mora sem filhos de } 18 \text { anos } \\
\text { e mais } \\
\text { Mora com filhos de } 18 \text { anos } \\
\text { e mais }\end{array}$ & - & & - & & - & & - & \\
\hline $\begin{array}{l}\text { Mora sem menores de } 18 \text { anos } \\
\text { Mora com menores de } 18 \text { anos }\end{array}$ & - & & - & & - & & - & \\
\hline \multicolumn{9}{|l|}{ Condição no domicílio } \\
\hline $\begin{array}{l}\text { Não é chefe da família } \\
\text { É chefe da família }\end{array}$ & - & & - & & - & & - & \\
\hline $\begin{array}{l}\text { Não é agregado ou parente } 2 \\
\text { Agregado ou outro parente }\end{array}$ & - & & - & & - & & - & \\
\hline
\end{tabular}

ferido, tendo maior intensidade com sua deficiente auto-avaliação da saúde do que com o risco de declarar-se doente. Seu efeito é pouco afetado com a introdução nos modelos das distintas tipologias testadas de arranjo familiar. A chance de um idoso com renda familiar per capita inferior a dois salários-mínimos declarar doenças é 51\% maior do que os que tem renda per capita familiar acima de cinco salários-mínimos, quando controlados por informante da seção de saúde, idade e alfabetismo (modelo 3 da Tabela 3). Homens idosos de famílias com uma renda per capita inferior a dois salários-mínimos têm maior risco de se declarar doente do que as mulheres idosas nas mesmas condições
( odds $=1,68$ e 1,35, Tabelas 4 e 5 respectivamente). A chance de declarar-se doente é também maior entre idosos com uma renda per capita entre dois e cinco salários-mínimos do que no grupo com renda per capita superior. $\mathrm{O}$ analfabetismo, que, além de refletir o status socioeconômico atual do idoso, dá conta de desvantagens acumuladas durante seu ciclo vital, é outro fator de risco para o idoso se declarar doente. Seu impacto é maior para o sexo feminino. Idosas analfabetas têm $29 \%$ de mais chance (Tabela 4) de ser doentes do que as que sabem ler e escrever, independentemente da idade e da renda familiar per capita (para os homens corresponde a odds $=1,15$, modelo 3, Tabela 5). 
Tabela 3

(continuação)

\begin{tabular}{|c|c|c|c|c|c|c|c|c|}
\hline & Modelo 5 & IC 95\% & Modelo 6 & IC 95\% & Modelo 7 & IC 95\% & Modelo 8 & IC 95\% \\
\hline \multicolumn{9}{|l|}{ Informante da seção de saúde } \\
\hline Própria pessoa & 1,00 & & 1,00 & & 1,00 & & 1,00 & \\
\hline Outra pessoa & $1,24^{\star}$ & $(1,16-1,34)$ & $1,23^{*}$ & $(1,15-1,33)$ & $1,20^{*}$ & $(1,12-1,29)$ & $1,21^{\star}$ & $(1,12-1,30)$ \\
\hline \multicolumn{9}{|l|}{ Sexo } \\
\hline Mulheres & 1,00 & & 1,00 & & 1,00 & & 1,00 & \\
\hline Homens & 0,59 & $(0,55-0,63)$ & $0,56^{*}$ & $(0,51-0,60)$ & $0,54^{*}$ & $(0,50-0,59)$ & $0,60^{*}$ & $(0,56-0,64)$ \\
\hline \multicolumn{9}{|l|}{ Idade } \\
\hline Menos 75 anos & 1 & & 1 & & 1 & & & \\
\hline De 75 anos e mais & $1,12^{\star}$ & $(1,04-1,21)$ & $1,14^{*}$ & $(1,05-1,23)$ & $1,13^{\star}$ & $(1,04-1,22)$ & $1,13^{\star}$ & $(1,05-1,23)$ \\
\hline \multicolumn{9}{|l|}{ Status socioeconômico } \\
\hline $\mathrm{RPC}$ mais de $5 \mathrm{SM}$ & & & 1 & & 1 & & & \\
\hline RPC menor $2 \mathrm{SM}$ & $1,51^{\star}$ & $(1,37-1,67)$ & $1,50^{*}$ & $(1,36-1,65)$ & $1,53^{\star}$ & $(1,39-1,69)$ & $1,53^{\star}$ & $(1,38-1,68)$ \\
\hline $\mathrm{RPC}$ de 2 a $5 \mathrm{SM}$ & $1,26^{\star}$ & $(1,14-1,40)$ & $1,26^{*}$ & $(1,13-1,40)$ & $1,27^{\star}$ & $(1,14-1,41)$ & $1,26^{\star}$ & $(1,14-1,40)$ \\
\hline Alfabetas & & & 1 & & 1 & & & \\
\hline Analfabetas & $1,22^{\star}$ & $(1,12-1,32)$ & $1,22^{\star}$ & $(1,13-1,32)$ & $1,23^{\star}$ & $(1,14-1,34)$ & $1,22^{\star}$ & $(1,13-1,33)$ \\
\hline \multicolumn{9}{|l|}{ Arranjo familiar } \\
\hline Mora com alguém & - & & - & & - & & - & \\
\hline Mora sozinho & & & - & & - & & - & \\
\hline Não mora só com cônjuge & 1 & & & & & & & \\
\hline Mora só com cônjuge & $1,13^{*}$ & $(1,04-1,23)$ & & & & & & \\
\hline Mora sem cônjuge & - & & NS & & NS & & - & \\
\hline Mora com cônjuge & & & & & - & & - & \\
\hline $\begin{array}{l}\text { Mora sem filhos de } 18 \text { anos } \\
\text { e mais }\end{array}$ & - & & - & & 1 & & NS & \\
\hline $\begin{array}{l}\text { Mora com filhos de } 18 \text { anos } \\
\text { e mais }\end{array}$ & & & & & $0,89^{\star}$ & $(0,82-0,96)$ & - & \\
\hline Mora sem menores de 18 anos & - & & - & & 1 & & 1 & \\
\hline Mora com menores de 18 anos & & & & & $0,88^{\star}$ & $(0,82-0,95)$ & $0,92^{*}$ & $(0,85-0,99)$ \\
\hline \multicolumn{9}{|l|}{ Condição no domicílio } \\
\hline Não é chefe da família & - & & 1 & & 1 & & & \\
\hline É chefe da família & & & $1,19^{*}$ & $(1,10-1,29)$ & $1,25^{\star}$ & $(1,15-1,37)$ & & \\
\hline Não é agregado ou parente 2 & - & & - & & - & & 1 & \\
\hline Agregado ou outro parente & & & & & - & & $0,90^{*}$ & $(0,81-0,99)$ \\
\hline
\end{tabular}

1 Que declaram pelo menos uma doença.

Estatisticamente significativas as variáveis ${ }^{\star} \mathrm{p}<0,001{ }^{* *} \mathrm{p}<0,05$.

2 Chefe, cônjuge ou filho.

Variáveis não incluídas no modelo.

NS: variável não significativa incluída no modelo.

As variáveis raça e área de residência (rural ou urbana) não foram significativas em nenhum dos modelos.

Observa-se maior impacto do status socioeconômico na auto-avaliação deficiente da saúde (modelos 3 ao 8 da Tabela 6). Idosos com maior renda per capita (categoria de referência) reportam melhor sua saúde do que aqueles com ingressos inferiores: idosos que residem em domicílios com menos de dois salários-mínimos per capita têm uma chance quase três vezes maior de declarar saúde deficiente do que os com mais de cinco salários-mínimos per capita. Já para os idosos com renda per capita fa- miliar entre dois e cinco salários-mínimos, essa chance é de quase duas vezes, mesmo depois de incluir o arranjo familiar no modelo (Tabela 6). A chance para um idoso analfabeto autoavaliar de forma negativa sua saúde é $60 \%$ maior do que para os idosos alfabetizados.

A introdução das variáveis socioeconômicas nos modelos das duas variáveis dependentes não modifica os diferenciais por gênero e reduz o efeito da variável idade do idoso (maior ou menor de 75 anos) nos modelos testados, pas- 
Tabela 4

Razão de chance (odds) dos modelos logísticos para mulheres idosas que se declaram doente. ${ }^{1}$

\begin{tabular}{|c|c|c|c|c|c|c|c|c|}
\hline & Modelo 1 & IC 95\% & Modelo 2 & IC $95 \%$ & Modelo 31 & IC 95\% & Modelo 4 & IC $95 \%$ \\
\hline \multicolumn{9}{|l|}{ Informante da seção de saúde } \\
\hline Própria pessoa & 1,00 & & 1,00 & & 1,00 & & 1,00 & \\
\hline Outra pessoa & $1,31^{\star}$ & $(1,18-1,45)$ & $1,36^{*}$ & $(1,22-1,51)$ & $1,31^{\star}$ & $(1,18-1,45)$ & $1,29^{\star}$ & $(1,16-1,45)$ \\
\hline \multicolumn{9}{|l|}{ Idade } \\
\hline Menos 75 anos & - & & 1,00 & & 1,00 & & 1,00 & \\
\hline De 75 anos e mais & & & $1,25^{\star}$ & $(1,12-1,39)$ & $1,20^{*}$ & $(1,07-1,34)$ & $1,13^{*}$ & $(1,01-1,27)$ \\
\hline Status socioeconômico & & & & & & & & \\
\hline $\mathrm{RPC}$ mais de $5 \mathrm{SM}$ & - & & - & & 1 & & 1 & \\
\hline RPC menor $2 \mathrm{SM}$ & & & & & $1,35^{\star}$ & $(1,17-1,55)$ & $1,29^{\star}$ & $(1,12-1,49)$ \\
\hline RPC de 2 a 5 SM & & & & & $1,19^{\star *}$ & $(1,03-1,39)$ & $1,19^{* *}$ & $(1,01-1,38)$ \\
\hline Alfabetas & - & & - & & 1 & & 1 & \\
\hline Analfabetas & & & & & $1,29^{*}$ & $(1,15-1,45)$ & $1,26^{*}$ & $(1,13-1,42)$ \\
\hline \multicolumn{9}{|l|}{ Arranjo familiar } \\
\hline Mora com alguém & - & & - & & - & & 1 & \\
\hline Mora sozinho & & & & & & & $1,19^{\star \star}$ & $(1,02-1,38)$ \\
\hline $\begin{array}{l}\text { Não mora só com cônjuge } \\
\text { Mora só com cônjuge }\end{array}$ & - & & - & & - & & - & \\
\hline Mora sem cônjuge & - & & - & & - & & - & \\
\hline Mora com cônjuge & & & & & & & & \\
\hline $\begin{array}{l}\text { Mora sem filhos de } 18 \text { anos } \\
\text { e mais }\end{array}$ & - & & - & & - & & - & \\
\hline $\begin{array}{l}\text { Mora com filhos de } 18 \text { anos } \\
\text { e mais }\end{array}$ & & & & & & & & \\
\hline $\begin{array}{l}\text { Mora sem menores de } 18 \text { anos } \\
\text { Mora com menores de } 18 \text { anos }\end{array}$ & - & & - & & - & & - & \\
\hline \multicolumn{9}{|l|}{ Condição no domicílio } \\
\hline $\begin{array}{l}\text { Não é chefe da família } \\
\text { É chefe da família }\end{array}$ & - & & - & & - & & - & \\
\hline $\begin{array}{l}\text { Não é agregado ou parente }{ }^{1} \\
\text { Agregado ou outro parente }\end{array}$ & - & & - & & - & & - & \\
\hline
\end{tabular}

(continua)

sando a razão de chance de 1,16 a 1,12 (modelo 2 , Tabela 3 ) para pessoas idosas que declaram alguma doença e de 1,42 a 1,32 (modelo 2, Tabela 6) para pessoas idosas com auto-avaliação negativa da saúde. Isso sugere que parte da explicação para os idosos mais velhos terem pior status de saúde deve-se ao incremento de desvantagem da situação socioeconômica nas idades mais avançadas.

Algumas das variáveis do tipo de arranjo familiar mostraram-se significativas e associadas, de forma diferenciada por gênero, com o status de saúde do idoso. Quando o tipo de arranjo familiar é incluído, aumenta o efeito do gênero no risco de declarar doenças (odds ratio de 0,61 até 0,54 , do modelo 4 ao 7 , Tabela 3 ), o que poderia estar indicando que a desvantagem da mulher no status da saúde é, em parte, resultan- te de suas "desvantagens", em comparação com os homens, nos tipos de seus arranjos familiares. Como foi comentado anteriormente, o padrão familiar dos homens é mais característico de família nuclear tradicional (presença de cônjuge e filhos), enquanto as mulheres dividemse entre aquelas que moram sozinhas, aquelas que moram com parentes ou só com filhos (entre outras opções). No caso da auto-avaliação deficiente de saúde, não é o gênero e sim a idade a variável que diminui seu impacto com a introdução das variáveis de arranjo familiar.

O efeito de morar sozinho é significativo para o risco de declarar-se doente, quando separados os modelos por gênero e controladas as condições socioeconômicas e sociodemográficas (Tabelas 4 e 5). Para a mulher, a probabilidade de sentir-se doente é maior quando mora sozi- 
Tabela 4

(continuação)

\begin{tabular}{|c|c|c|c|c|c|c|c|c|}
\hline & Modelo 5 & IC 95\% & Modelo 6 & IC 95\% & Modelo 7 & IC 95\% & Modelo 8 & IC $95 \%$ \\
\hline \multicolumn{9}{|l|}{ Informante da seção de saúde } \\
\hline Própria pessoa & 1,00 & & 1,00 & & 1,00 & & 1,00 & \\
\hline Outra pessoa & $1,31^{*}$ & $(1,18-1,45)$ & $1,28^{*}$ & $(1,15-1,42)$ & $1,27^{\star}$ & $(1,15-1,42)$ & $1,31^{*}$ & $(1,18-1,45)$ \\
\hline \multicolumn{9}{|l|}{ Idade } \\
\hline Menos 75 anos & 1,00 & & 1,00 & & 1,00 & & 1,00 & \\
\hline De 75 anos e mais & $1,20^{*}$ & $(1,07-1,34)$ & $1,18^{*}$ & $(1,05-1,32)$ & $1,17^{\star \star}$ & $(1,04-1,31)$ & $1,20^{*}$ & $(1,07-1,34)$ \\
\hline \multicolumn{9}{|l|}{ Status socioeconômico } \\
\hline $\mathrm{RPC}$ mais de $5 \mathrm{SM}$ & 1 & & 1 & & 1 & & 1 & \\
\hline RPC menor $2 \mathrm{SM}$ & $1,35^{*}$ & $(1,17-1,55)$ & $1,35^{*}$ & $(1,18-1,55)$ & $1,35^{*}$ & $(1,18-1,55)$ & $1,35^{\star}$ & $(1,17-1,55)$ \\
\hline RPC de 2a 5 SM & $1,19^{\star *}$ & $(1,03-1,39)$ & $1,20^{\star \star}$ & $(1,03-1,39)$ & $1,20^{\star *}$ & $(1,03-1,39)$ & $1,19^{* *}$ & $(1,03-1,39)$ \\
\hline Alfabetas & 1 & & 1 & & 1 & & 1 & \\
\hline Analfabetas & $1,29^{\star}$ & $(1,15-1,45)$ & $1,29^{*}$ & $(1,15-1,45)$ & $1,30^{*}$ & $(1,16-1,45)$ & $1,29^{\star}$ & $(1,15-1,45)$ \\
\hline \multicolumn{9}{|l|}{ Arranjo familiar } \\
\hline Mora com alguém & - & & - & & - & & - & \\
\hline Mora sozinho & - & & - & & - & & - & \\
\hline Não mora só com cônjuge & NS & & - & & & & & \\
\hline Mora só com cônjuge & & & - & & & & & \\
\hline Mora sem cônjuge & - & & 1 & & 1 & & - & \\
\hline Mora com cônjuge & & & $0,87^{\star \star}$ & $(0,79-0,96)$ & $0,86^{*}$ & $(0,78-0,95)$ & - & \\
\hline $\begin{array}{l}\text { Mora sem filhos de } 18 \text { anos } \\
\text { e mais }\end{array}$ & - & & & & 1 & & NS & \\
\hline $\begin{array}{l}\text { Mora com filhos de } 18 \text { anos } \\
\text { e mais }\end{array}$ & & & & & $0,89^{\star *}$ & $(0,80-0,99)$ & & \\
\hline $\begin{array}{l}\text { Mora sem menores de } 18 \text { anos } \\
\text { Mora com menores de } 18 \text { anos }\end{array}$ & - & & - & & NS & & NS & \\
\hline \multicolumn{9}{|l|}{ Condição no domicílio } \\
\hline $\begin{array}{l}\text { Não é chefe da família } \\
\text { É chefe da família }\end{array}$ & - & & NS & & NS & & & \\
\hline Não é agregado ou parente 2 & - & & - & & - & & NS & \\
\hline Agregado ou outro parente & & & & & & & - & \\
\hline
\end{tabular}

1 Que declaram pelo menos uma doença.

Estatisticamente significativas as variáveis ${ }^{\star} \mathrm{p}<0,001{ }^{\star *} \mathrm{p}<0,05$.

2 Chefe, cônjuge ou filho.

Variáveis não incluídas no modelo.

NS: variável não significativa incluída no modelo.

As variáveis raça e área de residência (rural ou urbana) não foram significativas em nenhum dos modelos.

nha do que quando mora com alguém $($ odds $=$ 1,19 , Tabela 4, modelo 4), enquanto para o homem os resultados não foram os esperados, já que funciona como um efeito protetor $(o d d s=$ 0,84 , Tabela 5 , modelo 4 ), o qual pode ser produto da pequena proporção de homens morando sozinhos. Entretanto, morar só com cônjuge tem um efeito negativo na morbidade dos homens idosos (odds=1,23 Tabela 5, modelo 5) e não significativo para as mulheres. O morar sozinho não tem relação significativa com a auto-avaliação da saúde do idoso.

Ser chefe no domicílio confere desvantagem na morbidade declarada para os homens idosos em relação aos que ocupam outra condição no domicílio (como agregado ou parente), controlado pela presença da esposa, de filhos menores de 18, de menores dividindo a residência e das condições socioeconômicas e sociodemográficas (nos modelos 6 e 7, odds= 1,19 e 1,21, Tabela 5). Conseqüentemente, ser agregado ou parente no domicílio dá um efeito protetor para a morbidade do homem idoso. No caso das mulheres, a condição que ocupam no domicílio não é significativa nem relevante.

A auto-avaliação deficiente da saúde não se modifica com a condição que o idoso ocupa no 
domicílio, nem com a maioria das variáveis de arranjos familiares introduzidas nos modelos. A presença de menores de 18 anos no domicílio diminuiu $10 \%$ o risco do idoso auto-avaliar sua saúde de forma deficiente em relação àqueles idosos sem presença de menores no domicílio (modelo 7 e 8, Tabela 6). Esses resultados são muito semelhantes quando realizados os modelos para cada sexo (tabelas não apresentadas), sendo esse risco ligeiramente menor para os homens. Vale destacar, também, que nesses modelos não apresentados em tabelas, observouse que os homens com piores condições socioeconômicas têm mais chance de avaliar sua saúde como deficiente do que mulheres idosas nas mesmas condições.

A presença de filhos maiores de 18 anos reduz a morbidade declarada com uma intensidade similar para o total dos idosos e também por gênero. Para os homens esse efeito deixa de ser significativo quando, além das condições socioeconômicas e sociodemográficas, é controlado pela presença de menores de 18 anos e a condição de agregado ou parente (modelo 8, Tabela 5). Vale destacar que um filho de 18 anos ou mais tem um efeito protetor quando o idoso homem é o chefe no domicílio, enquanto, quando ele é agregado ou parente, o efeito protetor corresponde à presença de menores de 18 anos (odds $=0,89$, Tabela 5, modelo 8). Para mulheres idosas a presença de filhos maiores de 18 anos tem um efeito protetor quando se controla por presença do esposo, e tem um efeito nulo quando se incorpora no modelo a condição de agregado ou parente, sendo que, no caso das mulheres, essa última variável não tem efeito quando interage com os outros fatores dos modelos 7 e 8 (Tabela 4).

A área de residência urbana/rural e a raça não têm efeito no status de saúde do idoso segundo os modelos testados.

\section{Conclusões}

Em países chamados desenvolvidos, diversidades de pesquisas já mostraram a relevância da estrutura familiar, de seus arranjos e das redes sociais no status de saúde dos idosos (Fuhrer \& Standsfeld, 2002; Mostafa \& Ginneken, 2000). Entretanto, ainda existem grandes desafios para explicar mecanismos e causalidade entre suporte social e o arranjo familiar na redução ou ampliação dos riscos de morbidade, mortalidade e tipo de auto-avaliação da saúde. Shye et al.
(1995), baseados em diversos estudos, apontam que alto nível de suporte contribui para melhor status de saúde de forma indireta quando o controle social exerce efeito nas práticas e comportamento de cuidados da saúde, quando atenua alguns fatores que podem exercer danos no indivíduo, e quando o suporte social e familiar ajuda no cuidado informal ou influencia no acesso e uso de serviços de saúde. Os autores referem outros estudos que mostraram a relação do tipo de suporte social com a condição do sistema imunológico, para afirmar que também podem ser diretos esses efeitos. Nos países menos desenvolvidos existe relativamente pouco estudo sobre esses tópicos. A escassa literatura focaliza principalmente o impacto da presença do esposo e presta menos atenção em outros aspectos como a convivência com filhos adultos, o morar sozinho, o impacto intermediário das condições socioeconômicas, sendo ainda menos conhecidos diferenciais por gênero e idade (Rahman, 1999).

No Brasil, essa problemática é particularmente importante. Não só porque o envelhecimento da população, como fenômeno demográfico universal, é um dos mais acentuados no atual conjunto dos países mais populosos do mundo (Moreira, 2000), mas também porque esse processo coincidiu com importantes transformações na rede de apoio ao idoso e na estrutura dos arranjos familiares. A respeito do último aspecto, Medeiros \& Osório (2002) mostraram que um dos efeitos da diminuição da fecundidade é o aumento do número de arranjos familiares, o que se deve, entre outras causas, ao fato de cada vez menos as pessoas, no envelhecimento, passarem a morar com outros núcleos familiares. O processo de industrialização e modernização e o número menor de membros na família, assim como a entrada da mulher no trabalho, também implicaram alterações na função tradicional da família como suporte e como rede de apoio de seus membros (Yazaki et al., 1991). A mulher adulta, tradicionalmente responsável pelos cuidados aos dependentes da família, dispõe cada vez menos de tempo para assumir o suporte dos parentes idosos (Goldani, 1985; Saad, 1998; Camarano, 2002). Entretanto, é importante considerar que, se é certo que com o desmantelamento das funções sociais do Estado e com a crise econômica das últimas décadas, a responsabilidade do cuidado do idoso poderia ficar mais restrita ao âmbito familiar, aumentando assim a "carga" para os familiares (Celade, 2002), também é certo que pelo empobrecimento, os 
Tabela 5

Razão de chance (odds) dos modelos logísticos para homens idosos que se declaram doente.1

\begin{tabular}{|c|c|c|c|c|c|c|c|c|}
\hline & Modelo 1 & IC 95\% & Modelo 2 & IC 95\% & Modelo 31 & IC 95\% & Modelo 4 & IC $95 \%$ \\
\hline \multicolumn{9}{|l|}{ Informante da seção de saúde } \\
\hline Própria pessoa & 1,00 & & 1,00 & & 1,00 & & 1,00 & \\
\hline Outra pessoa & $1,24^{*}$ & $(1,12-1,37)$ & $1,24^{*}$ & $(1,12-1,37)$ & $1,21^{*}$ & $(1,10-1,34)$ & $1,24^{*}$ & $(1,12-1,37)$ \\
\hline \multicolumn{9}{|l|}{ Idade } \\
\hline Menos 75 anos & - & & NS & & NS & & NS & \\
\hline De 75 anos e mais & & & & & & & & \\
\hline Status socioeconômico & & & & & & & & \\
\hline RPC mais de $5 \mathrm{SM}$ & - & & - & & 1 & & 1 & \\
\hline RPC menor $2 \mathrm{SM}$ & & & & & $1,68^{*}$ & $(1,46-1,92)$ & $1,67^{\star}$ & $(1,46-1,92)$ \\
\hline RPC de 2 a 5 SM & & & & & $1,33^{*}$ & $(1,14-1,54)$ & $1,32^{*}$ & $(1,14-1,54)$ \\
\hline Alfabetas & - & & - & & 1 & & 1 & \\
\hline Analfabetas & & & & & $1,15^{\star}$ & $(1,03-1,28)$ & $1,16^{* *}$ & $(1,03-1,30)$ \\
\hline \multicolumn{9}{|l|}{ Arranjo familiar } \\
\hline Mora com alguém & - & & - & & - & & 1 & \\
\hline Mora sozinho & & & & & & & $0,84^{\star *}$ & $(0,70-1,00)$ \\
\hline Não mora só com cônjuge & - & & - & & - & & - & \\
\hline Mora só com cônjuge & & & & & & & & \\
\hline Mora sem cônjuge & - & & - & & - & & - & \\
\hline Mora com cônjuge & & & & & & & & \\
\hline $\begin{array}{l}\text { Mora sem filhos de } 18 \text { anos } \\
\text { e mais }\end{array}$ & - & & - & & - & & - & \\
\hline $\begin{array}{l}\text { Mora com filhos de } 18 \text { anos } \\
\text { e mais }\end{array}$ & & & & & & & & \\
\hline Mora sem menores de 18 anos & - & & - & & - & & & \\
\hline Mora com menores de 18 anos & & & & & & & & \\
\hline \multicolumn{9}{|l|}{ Condição no domicílio } \\
\hline $\begin{array}{l}\text { Não é chefe da família ou } \\
\text { cônjuge do chefe } \\
\text { É chefe da família ou cônjuge } \\
\text { do chefe }\end{array}$ & - & & - & & - & & & \\
\hline $\begin{array}{l}\text { Não é agregado ou parente } 2 \\
\text { Agregado ou outro parente }\end{array}$ & - & & - & & - & & - & \\
\hline
\end{tabular}

(continua)

idosos, inclusive as mulheres, estão perpetuando sua participação no mercado de trabalho e contribuindo na economia das famílias, passando, em muitos casos, a sustentar outros membros jovens e adultos (Turra, 2001; Camarano \& Ghaouri, 1999; Camarano \& Pasinato, 2002).

No presente trabalho, baseado em dados do Brasil para 1998, mostraram-se importantes diferenciais entre gêneros em relação aos arranjos familiares dos idosos. Enquanto para os homens idosos a tipologia predominante é a tradicional família nuclear, em muitos casos em fase de expansão, para as mulheres a tipologia de família é heterogênea. Uma em cada duas idosas não mora com cônjuge, muitas moram sozinhas e daquelas que moram acompanhadas, um grande percentual não tem cônjuge e/ou mora com outros parentes. Assim, como afirma Goldani (1999), para o caso brasileiro a problemática de gênero intensifica-se com o envelhecimento pela acumulação das desvantagens experimentadas pelas mulheres no seu ciclo vital. Nascimento (2001) assinalava que, no Brasil, a menor sobremortalidade feminina e a maior propensão dos homens, quando viúvos, a recompor sua vida conjugal com mulheres mais jovens, caracterizam importantes diferenciais por gênero nessa etapa do ciclo vital.

$\mathrm{Na}$ análise dos dados encontrou-se que as mulheres idosas têm pior status de saúde que os homens. Contudo, o efeito do gênero é maior quando o status de saúde é avaliado pela autoreferência de doenças crônicas que quando é utilizada a autopercepção das condições de saú- 
Tabela 5

(continuação)

\begin{tabular}{|c|c|c|c|c|c|c|c|c|}
\hline & Modelo 5 & IC $95 \%$ & Modelo 6 & IC 95\% & Modelo 7 & IC 95\% & Modelo 8 & IC 95\% \\
\hline \multicolumn{9}{|l|}{ Informante da seção de saúde } \\
\hline Própria pessoa & 1,00 & & 1,00 & & 1,00 & & 1,00 & \\
\hline Outra pessoa & $1,20^{\star}$ & $(1,09-1,33)$ & $1,20^{*}$ & $(1,08-1,33)$ & $1,19^{*}$ & $(1,07-1,31)$ & $1,17^{\star}$ & $(1,06-1,29)$ \\
\hline \multicolumn{9}{|l|}{ Idade } \\
\hline Menos 75 anos & NS & & NS & & NS & & NS & \\
\hline \multicolumn{9}{|l|}{ De 75 anos e mais } \\
\hline \multicolumn{9}{|l|}{ Status socioeconômico } \\
\hline $\mathrm{RPC}$ mais de $5 \mathrm{SM}$ & 1 & & 1 & & 1 & & 1 & \\
\hline RPC menor $2 \mathrm{SM}$ & $1,70^{*}$ & $(1,49-1,95)$ & $1,67^{\star}$ & $(1,46-1,92)$ & $1,72^{\star}$ & $(1,50-1,98)$ & $1,72^{\star}$ & $(1,50-1,98)$ \\
\hline $\mathrm{RPC}$ de 2 a $5 \mathrm{SM}$ & $1,34^{\star}$ & $(1,15-1,55)$ & $1,32^{\star}$ & $(1,14-1,54)$ & $1,33^{\star}$ & $(1,15-1,55)$ & $1,34^{*}$ & $(1,15-1,56)$ \\
\hline Alfabetas & 1 & & 1 & & 1 & & 1 & \\
\hline Analfabetas & $1,17^{\star *}$ & $(1,04-1,31)$ & $1,17^{\star \star}$ & $(1,04-1,31)$ & $1,18^{*}$ & $(1,05-1,32)$ & $1,17^{\star \star}$ & $(1,04-1,31)$ \\
\hline \multicolumn{9}{|l|}{ Arranjo familiar } \\
\hline Mora com alguém & - & & - & & - & & - & \\
\hline Mora sozinho & - & & - & & - & & - & \\
\hline Não mora só com cônjuge & 1 & & - & & & & & \\
\hline Mora só com cônjuge & 1,23 & $(1,10-1,36)$ & - & & & & & \\
\hline Mora sem cônjuge & - & & 1 & & 1 & & - & \\
\hline Mora com cônjuge & & & $1,19^{* *}$ & $(1,05-1,34)$ & $1,21^{\star}$ & $(1,07-1,37)$ & - & \\
\hline $\begin{array}{l}\text { Mora sem filhos de } 18 \text { anos } \\
\text { e mais }\end{array}$ & - & & - & & - & & - & \\
\hline $\begin{array}{l}\text { Mora com filhos de } 18 \text { anos } \\
\text { e mais }\end{array}$ & & & & & $0,87^{\star *}$ & $(0,78-0,97)$ & & \\
\hline Mora sem menores de 18 anos & - & & - & & NS & & 1 & \\
\hline Mora com menores de 18 anos & & & & & & & $0,89^{\star *}$ & $(0,80-0,99)$ \\
\hline \multicolumn{9}{|l|}{ Condição no domicílio } \\
\hline $\begin{array}{l}\text { Não é chefe da família ou } \\
\text { cônjuge do chefe }\end{array}$ & - & & 1 & & 1 & & & \\
\hline $\begin{array}{l}\text { É chefe da família ou cônjuge } \\
\text { do chefe }\end{array}$ & & & $1,26^{\star *}$ & $(1,06-1,48)$ & $1,21^{\star \star}$ & $(1,02-1,43)$ & & \\
\hline Não é agregado ou parente 2 & - & & - & & - & & 1 & \\
\hline Agregado ou outro parente & & & & & - & & $0,79^{\star *}$ & $(0,67-0,94)$ \\
\hline
\end{tabular}

1 Que declaram pelo menos uma doença.

Estatisticamente significativas as variáveis ${ }^{*} \mathrm{p}<0,001{ }^{* *} \mathrm{p}<0,05$.

2 Chefe, cônjuge ou filho.

Variáveis não incluídas no modelo.

NS: variável não significativa incluída no modelo.

As variáveis raça e área de residência (rural ou urbana) não foram significativas em nenhum dos modelos.

de. Esses achados persistem após o controle pelas condições socioeconômicas (renda per capita familiar e analfabetismo), idade e arranjo familiar. Sendo assim, e acompanhando resultados de outras pesquisas (Lahelma \& Rahkonen, 1997; Arber \& Cooper, 1999; Molarius, 2002), confirma-se neste trabalho que diferenciais por gênero do status de saúde dos idosos variam de acordo com a medida de status de saúde usada. Arber \& Cooper (1999) assinalavam que tudo parece indicar que estamos diante de um novo paradoxo de diferenciais por gênero da saúde nas fases avançadas da vida, em que mulheres e homens avaliam de forma similar a condição de sua saúde, embora haja mais freqüência de incapacidades funcionais e doenças crônicas entre as mulheres idosas. Já Molarius (2002) tenta explicar esse paradoxo pela contribuição independente, e diferenciada por gênero, de diversas doenças crônicas e de seus sintomas na autoavaliação da saúde dos idosos. As mudanças estruturais nos padrões de vida femininos e nos papéis que ocupa a mulher na sociedade e na família também são apontadas como explicações para redução dos diferenciais de gênero na auto-avaliação da saúde (Nathanson, 1975). Mu- 
Tabela 6

Razão de chance (odds) dos modelos logísticos para pessoas idosas com auto-avaliação deficiente da saúde.

\begin{tabular}{|c|c|c|c|c|c|c|c|c|}
\hline & Modelo 1 & IC 95\% & Modelo 2 & IC 95\% & Modelo 31 & IC 95\% & Modelo 4 & IC 95\% \\
\hline \multicolumn{9}{|l|}{ Informante da seção de saúde } \\
\hline Própria pessoa & 1,00 & & 1,00 & & NS & & NS & \\
\hline Outra pessoa & $0,92^{\star \star}$ & $(0,86-0,97)$ & $0,88^{\star}$ & $(0,83-0,94)$ & & & & \\
\hline \multicolumn{9}{|l|}{ Sexo } \\
\hline Mulheres & 1,00 & & 1,00 & & 1,00 & & 1,00 & \\
\hline Homens & $0,80^{*}$ & $(0,76-0,85)$ & $0,81^{*}$ & $(0,77-0,86)$ & $0,81^{*}$ & $(0,77-0,85)$ & $0,81^{*}$ & $(0,77-0,85)$ \\
\hline \multicolumn{9}{|l|}{ Idade } \\
\hline Menos 75 anos & - & & 1 & & 1 & & 1 & \\
\hline de 75 anos e mais & & & $1,42^{*}$ & $(1,33-1,51)$ & $1,32^{*}$ & $(1,23-1,41)$ & $1,32^{*}$ & $(1,23-1,41)$ \\
\hline Status socioeconômico & & & & & & & & \\
\hline $\mathrm{RPC}$ mais de $5 \mathrm{SM}$ & - & & - & & 1 & & 1 & \\
\hline RPC menor $2 \mathrm{SM}$ & & & & & $2,72^{*}$ & $(2,51-2,96)$ & $2,72^{\star}$ & $(2,51-2,96)$ \\
\hline $\mathrm{RPC}$ de 2 a $5 \mathrm{SM}$ & & & & & $1,84^{*}$ & $(1,68-2,02)$ & $1,84^{*}$ & $(1,68-2,02)$ \\
\hline Alfabetas & - & & - & & 1 & & 1 & \\
\hline Analfabetas & & & & & $1,59^{*}$ & $(1,49-1,70)$ & $1,59^{*}$ & $(1,49-1,70)$ \\
\hline \multicolumn{9}{|l|}{ Arranjo familiar } \\
\hline $\begin{array}{l}\text { Mora com alguém } \\
\text { Mora sozinho }\end{array}$ & - & & - & & - & & NS & \\
\hline $\begin{array}{l}\text { Não mora só com conjugue } \\
\text { Mora só com conjugue }\end{array}$ & - & & - & & - & & - & \\
\hline $\begin{array}{l}\text { Mora sem conjugue } \\
\text { Mora com conjugue }\end{array}$ & - & & - & & - & & - & \\
\hline $\begin{array}{l}\text { Mora sem filhos de } 18 \text { anos } \\
\text { e mais } \\
\text { Mora com filhos de } 18 \text { anos } \\
\text { e mais }\end{array}$ & - & & - & & - & & - & \\
\hline $\begin{array}{l}\text { Mora sem menores de } 18 \text { anos } \\
\text { Mora com menores de } 18 \text { anos }\end{array}$ & - & & - & & - & & - & \\
\hline \multicolumn{9}{|l|}{ Condição no domicílio } \\
\hline $\begin{array}{l}\text { Não é chefe da família } \\
\text { É chefe da família }\end{array}$ & - & & - & & - & & - & \\
\hline $\begin{array}{l}\text { Não é agregado ou parentel } \\
\text { Agregado ou outro parente }\end{array}$ & - & & - & & - & & - & \\
\hline
\end{tabular}

lheres ganham cada vez mais independência financeira, moram com seus filhos sem a presença de cônjuge ou outro familiar e se incorporam ativamente no mercado de trabalho (Marsh \& Arber, 1993).

Uma das mais importantes contribuições deste trabalho é mostrar que, depois de controlar o efeito do informante das perguntas de saúde, da idade e da situação socioeconômica, o arranjo familiar tem relação significativa e é diferenciado por gênero com o status de saúde do idoso. Essa relação é mais intensa e diversa com a auto-referência de doenças crônicas que com a auto-avaliação da situação da saúde. Mulheres mostraram maior risco de declaração de doen- ças crônicas quando moravam sozinhas, enquanto a presença no domicilio de cônjuge e de filhos adultos funcionou como efeito protetor.

Quando os modelos testados neste trabalho controlam, entre as mulheres, a condição de agregado ou outro parente no domicílio, a condição do arranjo familiar deixa de ter efeito, predominando os efeitos das condições socioeconômicas. Para os homens, a condição que ocupam no domicílio tem um efeito significativo na declaração da doença. Ser agregado ou outro parente do chefe do domicílio funciona como efeito protetor, enquanto ser chefe de família aumenta a chance de auto-referenciar doenças crônicas (mesmo controlando pela pre- 
Tabela 6

(continuação)

\begin{tabular}{|c|c|c|c|c|c|c|c|c|}
\hline & Modelo 5 & IC $95 \%$ & Modelo 6 & IC 95\% & Modelo 7 & IC $95 \%$ & Modelo 8 & IC 95\% \\
\hline \multicolumn{9}{|l|}{ Informante da seção de saúde } \\
\hline Própria pessoa & NS & & NS & & NS & & NS & \\
\hline \multicolumn{9}{|l|}{ Outra pessoa } \\
\hline \multicolumn{9}{|l|}{ Sexo } \\
\hline Mulheres & 1,00 & & 1,00 & & 1,00 & & 1,00 & \\
\hline Homens & $0,81^{\star}$ & $(0,77-0,85)$ & $0,81^{\star}$ & $(0,77-0,85)$ & $0,80^{*}$ & $(0,75-0,84)$ & $0,80^{*}$ & $(0,75-0,84)$ \\
\hline \multicolumn{9}{|l|}{ Idade } \\
\hline Menos 75 anos & 1 & & 1 & & 1 & & 1 & \\
\hline De 75 anos e mais & $1,32^{\star}$ & $(1,24-1,41)$ & $1,32^{\star}$ & $(1,23-1,41)$ & $1,27^{\star}$ & $(1,19-1,36)$ & $1,27^{\star}$ & $(1,19-1,36)$ \\
\hline \multicolumn{9}{|l|}{ Status socioeconômico } \\
\hline $\mathrm{RPC}$ mais de $5 \mathrm{SM}$ & 1 & & 1 & & 1 & & 1 & \\
\hline RPC menor 2 SM & $2,72^{\star}$ & $(2,51-2,97)$ & $2,72^{\star}$ & $(2,51-2,96)$ & $2,75^{\star}$ & $(2,52-2,99)$ & $2,75^{\star}$ & $(2,52-2,99)$ \\
\hline $\mathrm{RPC}$ de 2 a $5 \mathrm{SM}$ & $1,85^{\star}$ & $(1,69-2,02)$ & $1,84^{\star}$ & $(1,68-2,02)$ & $1,84^{\star}$ & $(1,68-2,02)$ & $1,84^{\star}$ & $(1,68-2,02)$ \\
\hline Alfabetas & 1 & & 1 & & 1 & & 1 & \\
\hline Analfabetas & $1,60^{*}$ & $(1,49-1,71)$ & $1,59^{*}$ & $(1,49-1,70)$ & $1,64^{*}$ & $(1,53-1,76)$ & $1,64^{*}$ & $(1,53-1,76)$ \\
\hline \multicolumn{9}{|l|}{ Arranjo familiar } \\
\hline Mora com alguém & - & & - & & - & & - & \\
\hline \multicolumn{9}{|l|}{ Mora sozinho } \\
\hline Não mora só com cônjuge & 1 & & - & & - & & & \\
\hline Mora só com cônjuge & $1,12^{\star}$ & $(1,04-1,20)$ & & & & & & \\
\hline Mora sem cônjuge & - & & NS & & NS & & - & \\
\hline Mora com cônjuge & & & & & & & - & \\
\hline $\begin{array}{l}\text { Mora sem filhos de } 18 \text { anos } \\
\text { e mais }\end{array}$ & - & & - & & NS & & NS & \\
\hline \multicolumn{9}{|l|}{$\begin{array}{l}\text { Mora com filhos de } 18 \text { anos } \\
\text { e mais }\end{array}$} \\
\hline Mora sem menores de 18 anos & - & & - & & 1 & & 1 & \\
\hline Mora com menores de 18 anos & & & & & $0,88^{\star}$ & $(0,83-0,94)$ & $0,88^{\star}$ & $(0,83-0,94)$ \\
\hline \multicolumn{9}{|l|}{ Condição no domicílio } \\
\hline Não é chefe da família & - & & NS & & NS & & - & \\
\hline É chefe da família & & & & & & & & \\
\hline Não é agregado ou parentel & - & & - & & & & NS & \\
\hline Agregado ou outro parente & & & & & & & & \\
\hline
\end{tabular}

Estatisticamente significativas as variáveis ${ }^{*} \mathrm{p}<0,001{ }^{* *} \mathrm{p}<0,05$.

1 Chefe, cônjuge ou filho.

Variáveis não incluídas no modelo.

NS: variável não significativa incluída no modelo.

As variáveis raça e área de residência (rural ou urbana) não foram significativas em nenhum dos modelos.

sença do cônjuge, de filhos adultos e de menores de 18 anos). Homens que moram sozinhos ou que moram só com a cônjuge declararam menos doenças crônicas. Os resultados não são de todo consistentes com trabalhos como os de Rahman (1999) e Mostafa \& Ginneken (2000). Esses autores mostraram que em Bangladesh a presença do cônjuge é mais importante para homens que para mulheres. Entretanto, os autores também afirmam que é preciso conhecer muito mais sobre a influência dos tipos de rede social e do arranjo familiar na saúde do idoso, já que ainda não se dispõe de explicações conclusivas.

No que diz respeito à auto-avaliação da saúde dos idosos, o arranjo familiar que funcionou como efeito protetor foi a presença de menores de 18 anos no domicílio dos idosos. Notou-se que, quando introduzida essa variável no modelo, o diferencial por gênero e por idade diminui levemente, o que sugere que a presença de menores de 18 anos estaria explicando, em parte, a melhor auto-avaliação da saúde dos homens idosos; e que os mais idosos (maiores de 
75 anos) têm melhor percepção da saúde quando moram com pessoas de menor idade. O último poderia ser explicado, segundo análise de Shye et al. (1995), como efeito indireto na medida em que a companhia de menores poderia "atenuar" ou diminuir a percepção de elementos "estressantes" e de sintomas.

Outro importante achado do trabalho refere-se ao impacto das condições econômicas no status de saúde dos idosos. A menor renda per capita no domicílio ocasionou a maior chance de o idoso declarar doenças, com mais ênfase para os homens, e auto-avaliar de forma negativa sua saúde. Extremamente pronunciado entre os idosos brasileiros, o analfabetismo também está relacionado com o pior status da saúde. Como a literatura no tema tem mostrado, melhores condições econômicas atuam positivamente no acesso a cuidados de saúde e recursos materiais, nos hábitos saudáveis e no ambiente e espaço do idoso (Mackenbach et al., 1997; Backlund et al., 1996; Torrey et al., 1987), além de serem fatores que determinam desigualdades nas condições físicas e mentais (Lundberg, 1991). Nos modelos testados neste trabalho, tanto a renda per capita familiar quanto as condições de analfabetismo (que refletem desvantagens acumuladas no ciclo vital) foram as únicas variáveis que, além de significativas estatisticamente, não modificaram seu efeito. Confirmou-se também que o pior status de saúde dos mais idosos (maiores de 75 anos) deve-se, em parte, a maior desvantagem da situação socioeconômica nessa fase da vida mais avançada.
Por último, conclui-se que o estudo sobre os efeitos e relações dos arranjos familiares na saúde dos idosos e sua desigualdade por gênero precisa ser aprofundado desde diversas perspectivas de análise. A realização de inquéritos prospectivos poderia revelar maiores explicações sobre os mecanismos e temporalidade das relações desses eventos. Outras temáticas são também importantes na procura da causalidade sobre diferenciais na avaliação subjetiva da saúde pelos idosos. Alguns desses referem-se aos efeitos culturais. Embora reconhecendo que entre os idosos a auto-avaliação da saúde é um indicador que dá mais conta do estado clínico e funcional das habilidades cotidianas que nas idades mais jovens, pelo que resulta um bom indicador do estado de bem-estar pessoal (Bryant et al., 2001; Segovia et al., 1989; Should et al., 1996), estudos revelam a importante dependência de fatores culturais, psicológicos e emocionais. Num trabalho comparativo entre idosos dos Estados Unidos, da Índia e do Congo/Zaire, Westerhof e outros (2001) encontraram que, se para um idoso dos Estados Unidos ser saudável era um importante valor que significava manter a autonomia e as funções cognitivas (entre outras), para um idoso congolês sua saúde estava relacionada com o medo a morrer, declínio da mobilidade e com a incerteza do futuro dos filhos. No Brasil, não se dispõe até agora de inquéritos que permitam tal tipo de pesquisa. 


\section{Referências bibliográficas}

Arber S \& Cooper H 1999. Gender differences in health in later life: the new paradox? Social Science \& Medicine 48:61-76.

Auslander GK \& Litwin H 1990. Social support networks and formal help seeking: differences between applicants to social services and a nonapplicant sample. Journal of Gerontology: Social Sciences 45: S112-119.

Backlund E Sorlie PD \& Johnson NJ 1996. The shape of the relationship between income and mortality in the United States: evidence from the National Longitudinal Mortality Study. Annals of Epidemiology 6(1): 12-20

Bartley M, Popay J, \& Plewis I 1992. Domestic conditions, paid employment and women's experience of illhealth. Sociology of Health and Illness 14:313-343.

Berkman LF\& Syme SL 1979. Social network, host resistance and mortality; a nine-year follow-up study of Alameda Country residents. American Journal of Epidemiology 109:186-204.

Blazer DG. 1982. Social support and mortality in an elderly community population. American Journal of Epidemiology 115:686-94.

Bowling A 1991. Social support and social networks: their relationship to the successful survival of elderly people in the community. An analysis of concepts and a review of the evidence. Family Practice 8:68-83.

Bryant L, Beck A \& Fairclouhg DL 2000. Factors that contribute to positive perceived heatlh in an older population. Journal of Aging and Health 12(2):169-192.

Bryant L, Corbett K \& Kutner J 2001. In their own words: a model of healthy aging. Social Science \& Medicine 53:927-941.

Camarano AA \& El Ghaouri SK 1999. Idoso brasileiro: que dependência é essa?, pp. 281-306. In Camarano AA (org.) Muito além dos 60: os novos idosos brasileiros. IPEA, Rio de Janeiro.

Camarano AA \& Pasinato MT 2002. Envelhecimento, condições de vida e política previdenciária. Como ficam as mulheres da população brasileira: uma contribuição demográfica. Texto Para Discussão № 858 . IPEA, Rio de Janeiro.

Camarano AA 2002. Envelhecimento da população brasileira: uma contribuição demográfica. Texto Para Discussão № 858. IPEA, Rio de Janeiro.

Celade (Centro Latinoamericano y Caribeño de Demografía) 2002. Los adultos mayores en América Latina y el Caribe. Datos e indicadores. Santiago de Chile. Disponível em <www.eclac.cl/celade/noticias/paginas/ 3/9353/boletin_envejecimiento.PDF $>$

De Vos S \& Holden K 1988. Measures comparing living arrangements of the elderly: an assessment. Population and Development Review 14(4):689-704.

Fuhrer R \& Standsfeld S 2002. How gender affects patterns of social relations and their impact on health: a comparison of one or multiple sources of support form “close persons". Social Science and Medicine 54: 811-825.

Goldani AM 1985. Estrutura familiar e transição demográfica: o caso do Brasil, pp. 141-190. In Informe Demográfico, São Paulo, v. 17.

Goldani AM 1999. Mulheres e envelhecimento: desafios para novos contratos intergeracionais e de gênero. In
Camarano AA (org.). Muito além dos 60: os novos idosos brasileiros. IPEA, Rio de Janeiro.

Grundy E, Bowling A \& Farquhar M 1996. Social support, life satisfaction and survival at older ages, pp. 135156. In Graziella C \& Alan DL (ed.). Health and mortality among elderly populations. Clarendon Press-International Union for the Scientific Study of Population [IUSSP], Oxford, Inglaterra-Liège, Bélgica.

Guzmán JM \& Hakkert 2000. Some social and economic impacts of the ageing process in Latin American countries. In Anais da XXIV IUSSP General Conference, Salvador.

Holden KA 1988. Poverty and living arrangements among older women are changes in economic well-being underestimated? The Journal of Gerontology 43(1):S22S27.

Hughes ME \& Waite L 2002. Health in household context: living arrangements and health in late middle-age. Journal of Health and Social Behavior 43:11-21.

IBGE, 2000. Pesquisa Nacional por Amostra de Domicilios1998, Rio de Janeiro.

Idler E \& Benyamini Y 1997. Self-rated health and mortality: a review of twenty-seven studies. Journal of Health and Social Behavior 38:21-37.

Idler E 1993. Age differences in self-assessment of health: age changes, cohort differences or survivorship? The Journal of Gerontology (48):S289-300.

Jylhä M, Guralnik JM, Ferrrucci L, Jokela J \& Heikkinen E 1998. Is self-rated health comparable across cultures and genders? The Journals of Gerontology. Series B, Psychological Sciences and Social Sciences, 53(3): S144-152.

Kaplan GA \& Camacho T 1983. Perceived health and mortality: a nine year follow-up of the human population laboratory cohort. American Journal of Epidemiology 117:292-304.

Lahelma E \& Rahkonen O 1997. Health inequalities in modern societies and beyond. Edição especial de Social Science and Medecine 44(6):721-910.

Lahelma E, Martikainen P, Rahkonen O \& Silventoinen K 1999. Gender differences in illhealth in Finland: patterns, magnitude and change. Social Science \& Medicine 48:7-19.

Lee ES, Forthofer RN \& Lorimer RJ. 1989. Analyzing complex survey data. SAGE Publications Inc., USA.

Litwin H 1998. Social network type and health status in a national sample of elderly in Israelis. Social Science \& Medicine 46 (4-5):599-609.

Lundberg O 1991. Causal explanations for class inequality in health: an empirical analysis. Social Science \& Medicine 32:385-393.

Macintyre S, Hunt, K \& Sweeting, H 1996. Gender differences in health: are things really as simple as they seem? Social Science and Medicine 42:617-624.

Mackenbach JP, Kunst AE, Cavelaars AE, Groenhof F, Geurts JM \& the EU. Working Group on Socioeconomic Inequalities in Health 1997. Socioeconomic inequalities in morbidity and mortality in western Europe. The Lancet, vol. 349 (Issue 9066):1655-1659

Manderbacka K, Kareholt I, Martikainen P \& Lundberg O2002. The effect of point of reference on the association between self-rated health and mortality. Social Science \& Medicine (no prelo). 
Marks NF 1996. Socioeconomic status, gender and health at midlife: evidence form the Wisconsin Longitudinal Study. Research in the Sociology of Health Care 13: 133-150.

Marsh C \& Arber S. (eds.) 1993. Families and households: divisions and change. Macmillan, Londres.

Medeiros M, Osório RG \& Varella S 2002. O levantamento de informações sobre as famílias nas PNADs de 1992 a 1999. Texto para Discussão № 860. IPEA, São Paulo.

Medeiros M \& Osório R 2002. Mudanças nas famílias brasileiras. A composição dos arranjos familiares entre 1978 e 1998. Texto Para Discussão № 886. IPEA, Rio de Janeiro.

Molarius A \& Janson S 2002. Self-rated health, chronic diseases, and symptoms among middle-aged and elderly men and women. Journal of Clinical Epidemiology 55:364-370.

Mor-Barak M \& Miller LS 1991. A longitudinal study of the causal relationship between social networks and health of the poor frail elderly. Journal of Applied Gerontology 10:293-310.

Moreira M 2000. Envelhecimento da população brasileira: aspetos gerais, pp. 25-56. In L Wong (org.). O envelhecimento da população brasileira e o aumento da longevidade. Subsídios para políticas orientadas ao bemestar do idoso. Editora CEDEPLAR-UFMG-ABEP, Belo Horizonte.

Mossey JM \& Shapiro E 1982. Self-rated health: a predictor mortality of the elderly. American Journal of Public Health 72:800-808.

Mostafa G \& Van Ginneken, J 2000. Trends in and determinants of mortality in the elderly population of Matlab, Bangladesh. Social Science \& Medecine 50: 763-771.

Nascimento MR 2001. Feminização do envelhecimento populacional: expectativas e realidades de mulheres idosas quanto ao suporte familiar, pp. 191-218. In L Wong (org.). O envelhecimento da população brasileira e o aumento da longevidade. Subsídios para políticas orientadas ao bem-estar do idoso. Editora CEDEPLARUFMG-ABEP, Belo Horizonte.
Nathanson CA 1975. Illness and the feminine role: a theoretical review. Social Science and Medicine 9:57-62.

Omam D \& Reed D 1998. Religion and mortality among the community-dwelling elderly. American Journal of Public Health vol. 38, № 10(1):469-75.

Rahman MO 1999. Age and gender variation in the impact of household structure on elderly mortality. International Journal of Epidemiology 28:485-491.

Saad P 1998. Transferências de apoio intergerações na cidade de Fortaleza. In Anais do XI Encontro $\mathrm{Na}$ cional de Estudos Populacionais da ABEP, Caxambu.

Segovia J, Bartlett RF \& Edwards AC 1989. An empirical analysis of the dimensions of health status measures. Social Science and Medicine 29:761-768.

Should S, Congdon P \& Curtis S 1996. Modelling inequality in reported long term illness in the UK: combining individual and area characteristics. Journal of Epidemiology and Community Health 50:266-276.

Shye D, Mullooly JP, Freeborn DK \& Pope CR 1995. Gender differences in the relationship between social network support and mortality: a longitudinal study of an elderly cohort. Social Science and Medicine, vol. 41, No. 7:935-947. Tarrytown, Nova York-Oxford, Inglaterra.

Torrey BB, Kinsella K \& Taeuber CM 1987. An aging world. International Population Reports, Series P-95, No. 78. U.S. Bureau of the Census, Washington, D.C.

Turra CM 2001. Intergenerational accounting and economic consequences of aging in Brazil. In Anais da XXIV IUSSP General Conference, Salvador.

Westerhof G, Katzko M, Dittmann-Kohli F \& Hayslip B 2001. Life contexts and health-related selves in old age: perspectives from the United States, India and Congo/Zaire. Journal of Aging Studies 15(2):105-126.

Yazaki L, Melo AV \& Ramos LR 1991. Perspectivas atuais do papel da família ao envelhecimento populacional: um estudo de caso. Informe Demográfico, 24(11):1196.

Artigo apresentado em 15/7/2002

Aprovado em 9/9/2002

Versão final apresentada em 30/9/2002 